ИЗВЕСТИЯ АКАДЕМИИ НАУК ЭСТОНСКОП ССР. ТОМ 19

ХИМИЯ * ГЕОЛОГИЯ. 1970, № 4

\author{
Т. ПЕХК, Ю. ЛИЛЛЕ, Э. ЛИППМАА, Л. БНТТЕР
}

\title{
ХИМИЧЕСКИЕ СДВИГИ УГЛЕРОДА-13 АЛКИЛРЕЗОРЦИНОВ
}

При проведении цикла работ по изучению алкилрезорщинов $\left[{ }^{1}\right]$ особое значение прнобрели методы определения их структуры. Из спектральных методов для этой цели прнменялись ИК и УФ спектрофотометрия $\left[{ }^{2-5}\right]$, масс-спектрометрия $\left[{ }^{6,7}\right]$ и ядерный магнитный резонанс (ЯМР) на протонах $\left[{ }^{2}\right]$. ЯМР-спектры углерода-13 алкилрезорцинов не изучены, хотя с точки зрения определения структуры углеродного скелета молекулы они имеют известные преимущества перед другими спектрами. В литературе имеются данные только о протонных химических сдвигах незамещенного резорцина $\left[{ }^{8}\right]$ и 5-метилрезорцина [ $\left.{ }^{9}\right]$. По виду спектра ароматических протонов удается определить место присоединения заместителя, но определение строения алкильного радикала затруднено.

Сильная зависимость химических сдвигов углерода от разветвленности алкильных трупп $\left[{ }^{10}\right]$ дает возможность определить структуру сложных алкильных цепей с больжшим количеством углеродных атомов., В то же время благодаря аддитивности углеродных химических сдвигов по спектрам ЯМР легко определяется место присоединения алкильного остатка.

В последнее время накоплен значительный материал по резонансу углерода-13 в арсматических соединениях, указывающий на аддитивность химических сдвигов. Однако в определенных условиях имеют место более или менее существенные отклонения. Проведенное исследование подтверждает аддитивность химических сдвигов в спектрах алкилрезорцинов, однако указывает на значительные пространственные взаимодействия .в молекулах 2- и 4-алкилрезорцинов.

\section{Экспериментальная часть}

2-Алкилрезорцины синтезированы через диметиловый эфир 2-литийрезорцина [1'], 5-метил-, этил- и пропилрезорцины получены из произ. водных циклогександиона-1,3 $\left.{ }^{12}\right]$, 5-гептилрезорцин получен восстановлением 3,5-дигидроксифенилгексилкетона [13], а 4-алкилрезорцины синтезированы восстановлением соответствующих кетонов по Клемменсену $\left[{ }^{14}\right]$. Чистота всех соединений проверялась методом газовой хроматографии и составляла не менее $95 \%$.

Спектры ЯМР углерода-13 были сняты при частоте 15,1 Мгц на универсальном спектрометре, работающем по методу разделения времени $\left.{ }^{15}\right]$. Химические сдвиги определялись из спектров поглощения с применением двойного резонанса. При этом сильное возмущающее ВЧ-поле перестраивалось во время каждой развертки на резонанс с протонами, связанными с насыщенными и ненасыщенными атомами углерода. Растворителем служил метиловый спирт. Полученные спектры иллюстрирует приведенный на рисунке спектр ЯМР ${ }^{13} \mathrm{C}$ 4-н-бутилрезорцина. 


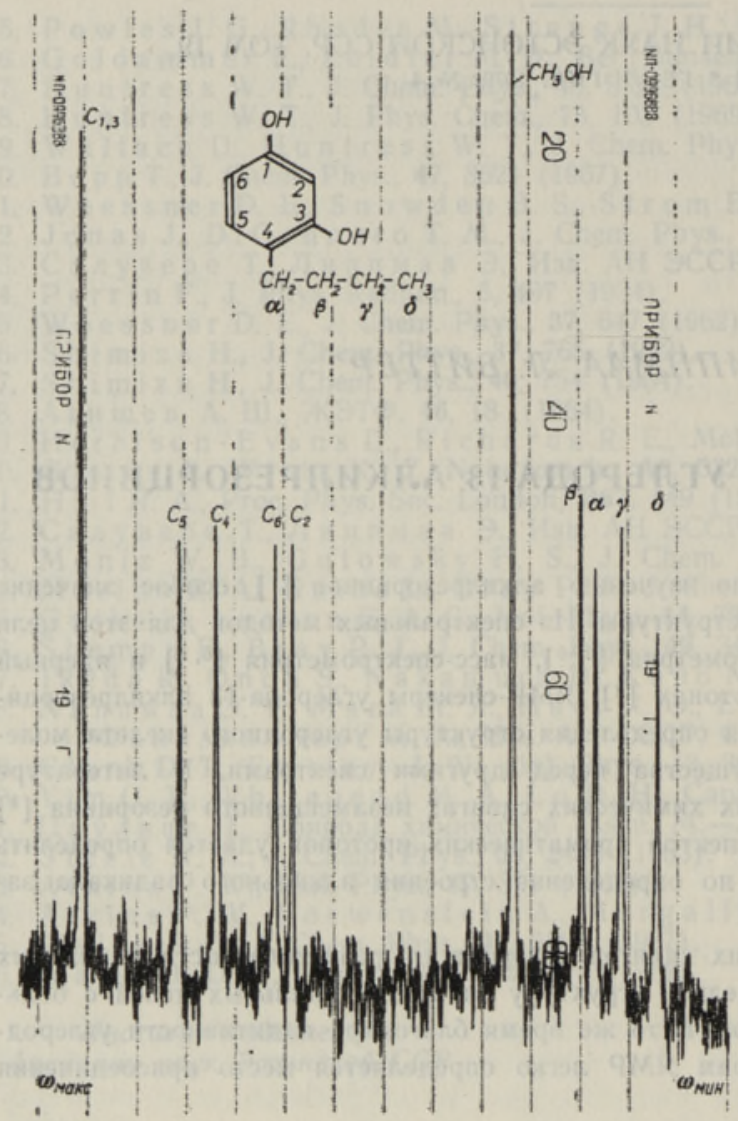

Спектр абсорбции двойного резонанса раствора 4-н-бутилрезорцина в метиловом спирте. Скорость разведтки 15 гц/сек.
Можно различать две группы сигналов: в более сильном поле резонируют углеродные атомы растворнтеля. и н-бутильной группы, а в. слабом поле ароматические углеродные атомы. Применялись невращающиеся ампулы диаметром 15 мм. Так. как растворение фенолов в. спиртах сопровождается комплексообразованием [16], то для оценки влияния концентрации метилового спирта на экранирование алкилрезорцинов были измерень химические сдвиги чистого резорцина при температуре около $115^{\circ} \mathrm{C}$, а также растворов резорцина в метиловом спирте при концентра-циях $4 ; 15 ; 30 ; 45$ и $70 \%$. резорцина в метаноле. При переходе от чистого резорцина к насыщенному $(70 \%)$, раствору в метаноле наблюrдается увеличение экраниро-вания С-2, C-4,6 и С-5 атомов углерода на 1,$3 ; 1,4$ n 0,6 м. д. соответственно, а в то же время экранирование: C-1,3 практически не меня-ется. Дальнейшее разбавле-ние раствора до $4 \%$ приводит к дополнительному увеличению экранирования С-5 на 0,9 ж. б. к. C-4,6 на 1,2 м.д. и к уменьшению экранирования С-1,3 на 1,6 м.д. Разбавление насыщенного раствора не оказывает заметного влияния на сдвиг атома C-2. Неодинаковый ход кривых разбавления указывает на сложность сольватационных процессов растворов фенолов в спиртах. Следует указать, что в изменении химических сдвигов резорцина имеется некоторая аналогия с изменением химических сдвигов оксибензола в растворе метанола с прибавкой метилата натрия [17].

Хотя суммарные изменения экранирования атомов резорцина довольно большие, в пределах изменения концентраций изученных алкилрезорцинов (см. табл. 1, 3) это приводит лишь к незначительной дополнительной погрешности, не превышающей $\pm 0,2$ м.д. при изменении концентрации алкилрезорцинов на 10\%. Данные измеренных химических сдвигов углерода-13 приведены в табл. 1 и 3 . Химические сдвиги измерены относктельно внешнего эталона $\mathrm{CS}_{2}$. Воспр оизводимость результатов нзмерений около $\pm 0,2$ м. . При отнесении спектральных линий легко определить сигналы от алкильного остатка и от ароматических атомов углерода, так как разница в экранировании $s p^{2}-$ и $s p^{3}$-гибридизованных атомов углерода в данном случае составляет от 60 до 90 м.д. Для отнесения линий в алкильном радикале применялось сравнение с химическимі сдвигами $H$-алканов $\left[{ }^{10}\right]$, алкилбензолов $\left[{ }^{18}\right]$ и алкилциклоалкенов $\left[{ }^{19}\right]$. 
Имеющиеся регулярности в спектрах алкилзамещенных циклических соединений в большинстве случаев дают возможность для однозначного отнесения всех линий. Для отнесения химических сдвигов $\alpha$ - и $\beta$-углеродных атомов в 4-амил-, 4-гексил-, 4-гептил- и 4-нонилрезорцинах применялось селективное насыщение протонов, находящихся в $\alpha$-положениях к ароматическому ядру. Эти протоны дают резонанс в более слабом поле, чем остальные протоны алкильного радикала, присоединенного к арсматическому ядру (ср. средний химический сдвиг алифатических метиленовых групп в углеводородах $8,7 \tau$ со сдвигом метиленовой группы в этилбензоле $7,38 \tau\left[{ }^{20}\right]$ ). Таким образом удается однозначно отнести различающиеся на менее, чем 1 м.д. спектральные линии.

Отнесение линий ароматических углеродных атомов основывается на определении мультиплетности сигналов в спектрах монорезонанса и на сравнительном анализе химических сдвигов. В последнем случае полученные химические сдвиги сравниваются со сдвигами, рассчитанными на основе аддитивности химических сдвигов углерода.

\section{Результаты и обсуждение}

2 - Ал ки л р езо рцины. Спектры 2- и 5-замещенных резорцинов должны в общем случае содержать одинаковое на основе симметрии количество линий, но в то же время их очень легко различать хотя бы по химическому сдвигу атома С-2 в цикле.

В 2-замещенных алкилрезорцинах в положении 2 наблюдается парамагнитный сдвиг по сравнению со сдвигом С-2 в резорцине; при этом уменьшение экранирования С-2 примерно равно уменьшению экранирования замещенного атома в соответствующих алкилбензолах $\left[{ }^{18}\right]$.

Таблица 1

Химические сдвиги ${ }^{13} \mathrm{C}$ в 2- и 5-алкилрезорцинах $\left(\delta \mathrm{cs}_{2}\right)$

\begin{tabular}{|c|c|c|c|c|c|c|c|c|c|c|c|c|}
\hline & & & & & & \multicolumn{7}{|c|}{ Алкильный остаток } \\
\hline $\begin{array}{l}\text { Замес- } \\
\text { титель }\end{array}$ & $\mathrm{CH}_{3} \mathrm{BH}$ & C-1,3 & $C-2$ & C- 4,6 & C-5 & $\alpha$ & $\beta$ & $v$ & $\delta$ & $\varepsilon$ & $\xi$ & $\eta$ \\
\hline
\end{tabular}

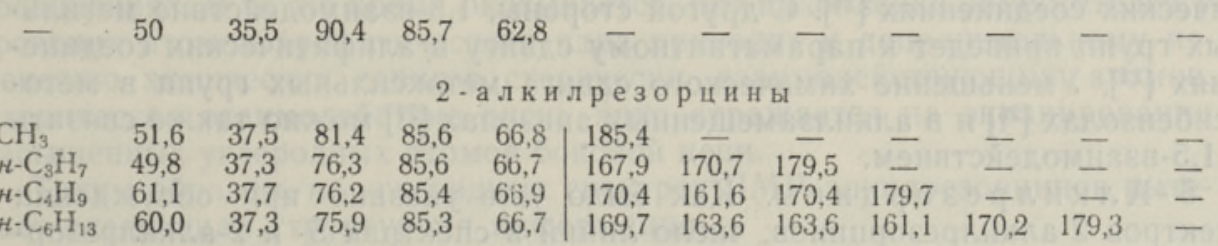

\begin{tabular}{llllll|lllllll}
$\mathrm{CH}_{3}$ & 47,8 & 35,8 & 93,3 & 85,0 & 52,4 & 172,6 & $\overline{3}$ & - & - & - & - & - \\
$\mathrm{C}_{2} \mathrm{H}_{5}$ & 49,4 & 35,6 & 92,9 & 86,2 & 45,8 & 164,4 & 178,3 & $\overline{1}$ & - & - & - & - \\
$\mathrm{H}-\mathrm{C}_{3} \mathrm{H}_{7}$ & 46,6 & 36,2 & 93,0 & 85,7 & 47,5 & 155,6 & 169,3 & 180,0 & - & - & $\overline{-}$ \\
$\mathrm{H}-\mathrm{C}_{7} \mathrm{H}_{15}$ & 46,7 & 35,4 & 93,0 & 85,9 & 47,8 & 157,3 & 162,0 & 163,9 & 163,9 & 161,3 & 170,6 & 179,6
\end{tabular}

В спектрах 2-алкилрезорцинов наблюдается аналогия с алкилбензолами также по величине эффектов замещения в других положениях цикла. Меньше всего меняется экранирование атомов, находящихся в метаположении от заместителя. В пара-положении возникает диамагнитный сдвиг около 4 м.д. (в алкилбензолах около 3 м.д. $\left.\left[{ }^{18}\right]\right)$. Если в алкилбен- 
золах изменение экранирования орто-атомов незначительное, то в 2 -алкилрезорцинах из-за стерического взаимодействия экранирование углеродных атомов, связанных с кислородом, увеличено на 2 м.д. по сравнению с незамещенным резорцином.

Для оценки влияния гидроксильных групп на алкильную группу измеренные сдвиги можно сравнить со сдвигами алкильных групп алкилбензолов. В табл. 2 приведегіы химические сдвиги алкильных групп в алкилбензолах $\left[{ }^{18}\right]$, среди которых сдвиги $H$-пропилбензола и $H$-гексилбензола приведены впервые.

Таблици 2

Химические сдвиги ${ }^{13} \mathrm{C}$ насыщенных атомов $н$-алкилббензолов $\left(\delta \mathrm{cs}_{2}\right)$

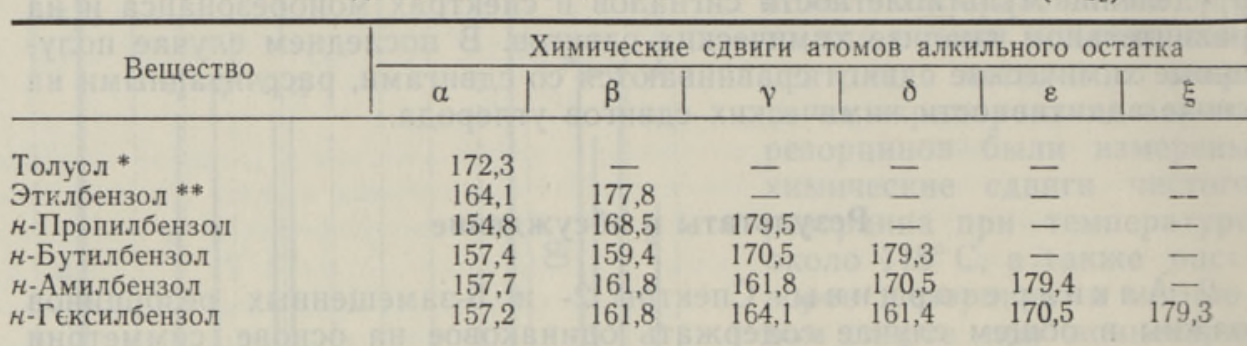

* 171,8 по $\left[{ }^{21}\right], 172,4$ по $\left[{ }^{22}\right]$.

** 164,3 и 177,9 по $\left[{ }^{23}\right]$.

Как и в $о$-крезоле $\left[{ }^{23}\right]$, в $\boldsymbol{\alpha}$-положении относительно ароматического ядра наблюдается увеличение экранирования, при этом относительный диамагнитный сдвиг, равный 13 м.д., намного больше, чем изменение сдвига 2-метильной группы в о-крезоле (3,5 $м$. д.) или в 1,2,3-триметилбензоле $\left(6,3\right.$ м.д. $\left.\left[{ }^{22}\right]\right)$. Этого и. следовало ожидать, так как в 2-алкилзамещенных резорцинах имеются наиболее благоприятные условия для 1,4-взаимодействия между гидроксильными группами и $\alpha$-углеродными атомами боковой цепи. Примечательным является относительный диамагнитный сдвиг, равный 2 м.д. для $\beta$-углеродных атомов. Увеличение экранирования за счет 1,5-взаимодействия отмечено нами также в бициклических соединениях $\left[{ }^{24}\right]$. С другой стороны, 1,5-взаимодействие метильных групп приведет к парамагнитному сдвигу в алифатических соединениях [25]. Уменьшение химического сдвига метоксильных групп в метоксибензолах $\left[{ }^{26}\right]$ и в алкилзамещенных анизолах $\left[{ }^{27}\right]$ можно также связать с 1,5-взаимодействием.

5 - Алки л резо рцины. Как было уже указано при обсуждении спектров 2-алкилрезорцинов, число линий в спектрах 5- и 2-алкилрезорцинов одинаковое. Благодаря влиянию алкильных групп атомы С-2 имеют диамагнитный сдвиг около 3 м.д. Химические сдвиги С-1,3 практически совпадают со сдвигом замещенных атомов резорцина. В положениях 4,6 и 5 имеется также аналогия с алкилбензолами. Экранирования насыщенных атомов в 5-алкилрезорцинах практически совпадают с данными для алкильных групп в алкилбензолах, чего и следовало ожидать на основе отсутствия взаимодействия заместителей, находящихся в мета-положениях.

4 - А л к и л езо рци ны. Хотя в общем случае можно предполагатьнеравенства химических сдвигов всех ароматических углеродных атомов. в изученных 4-алкилрезорцинах, сдвиги С-1 и С-3 при данной разрешаю- 
Таблица 3

Химические сдвиги ${ }^{13} \mathrm{C}$ в 4 -алкилрезорцинах $\left(\delta \mathrm{cs}_{2}\right)$

\begin{tabular}{|c|c|c|c|c|c|c|c|c|c|c|c|c|c|c|c|}
\hline \multirow{2}{*}{$\begin{array}{l}\text { За- } \\
\text { мес- } \\
\text { титель }\end{array}$} & \multirow{2}{*}{$\begin{array}{c}\text { Конц. } \\
\text { B } \\
\mathrm{CH}_{3} \mathrm{OH}\end{array}$} & \multirow{2}{*}{ C-1,3 } & \multirow[b]{2}{*}{ C-2 } & \multirow[b]{2}{*}{ C-4 } & \multirow[b]{2}{*}{ C-5 } & \multirow[b]{2}{*}{ C-6 } & \multicolumn{9}{|c|}{ Алкильная грушпа } \\
\hline & & & & & & & $\alpha$ & $\beta$ & $\gamma$ & $\delta$ & 8 & $\xi$ & $\eta$ & $\theta$ & t \\
\hline
\end{tabular}

\begin{tabular}{|c|c|c|c|c|c|c|c|c|c|c|c|c|c|c|c|}
\hline- & 50 & 35,5 & 90,4 & 85,7 & 62,8 & 85,7 & - & - & - & - & - & - & - & - & - \\
\hline $\mathrm{CH}_{3}$ & 37,0 & 37,8 & 90,8 & 77,3 & 62,2 & 86,6 & 178,9 & - & - & - & - & - & - & - & - \\
\hline $\mathrm{C}_{2} \mathrm{H}_{5}$ & 52,8 & 38,4 & 90,3 & 70,5 & 63,4 & 86,2 & 171,0 & 179,9 & - & - & - & - & - & - & - \\
\hline H. $\mathrm{C}_{3} \mathrm{H}_{7}$ & 30,3 & 37,5 & 90,4 & 72,4 & 62,7 & 86.5 & 161,7 & 169,9 & 179,9 & - & - & - & - & - & - \\
\hline $\mathrm{H}-\mathrm{C}_{4} \mathrm{H}_{9}$ & 65,0 & 38,1 & 89,9 & 71,4 & 62,4 & 85,8 & 164,1 & 160,6 & 170,6 & 179,5 & - & - & - & - & - \\
\hline $\mathrm{H}-\mathrm{C}_{5} \mathrm{H}_{10}$ & 55,0 & 37,8 & 90,1 & 71,6 & 62,5 & 86,0 & 163,8 & 163,2 & 161,3 & 170,5 & 179,4 & - & - & - & - \\
\hline $\mathrm{H}-\mathrm{C}_{6} \mathrm{H}_{13}$ & 57,5 & 37,7 & 90,0 & 71,6 & 62,5 & 85,9 & 163,8 & 162,8 & 163,8 & 161,1 & 170,4 & 179,3 & - & - & - \\
\hline$H-\mathrm{C}_{7} \mathrm{H}_{15}$ & 54,1 & 37,7 & 90,2 & 71,8 & 62,6 & 86,1 & 163,8 & 162,8 & 163,8 & 163,8 & 161,1 & 170,5 & 179,5 & - & - \\
\hline$\mu \cdot \mathrm{C}_{9} \mathrm{H}_{19}$ & 56,2 & 37,7 & 90,2 & 71,8 & 62,6 & 86,1 & 163,7 & 162,8 & 163,7 & 163,7 & 163,7 & 163,7 & 161,1 & 170,5 & 79 \\
\hline
\end{tabular}

щей способности (около 0,2 м.д.) совпадают (см. табл. 3). Это нескольконесжиданно, так как алкильные заместители в алкилбензолах неодинаково влияют на орто- и пара-положения. Следовательно, можно было ожидать, что экранирование С-1 примерно на 2,5-3 м.д. более диамагнитное, чем для С-3. Но с другой стороны, стерическое взаимодействие должно привести к некоторому увеличению экранирования С-3, как и в 2 -алкилрезорцинах (положения С-1 и С-3). Этим и объясняется близость. химических сдвигов С-1 и С-3 в 4-алкилрезорцинах.

Влияние алкильных заместителей на химические сдвиги С-2,6 и С-4 имєет близкую аналогию с алкилбензолами.

Стерическое взаимодействие с алкильной группой в 4-замещенных резорцинах должно быть слабее, чем в 2-замещенных производных. Этоотражается на химических сдвигах $\alpha$-углеродных атомов боковой цепи. Относительные сдвиги здесь меньше (около 6,5 м.д.), чем в 2-производных, но все-таки больше, чем в $о$-крезоле [23]. Увеличение экранирования $\beta$-углеродного атома хотя и заметно $(1-2$ м.д.), но меньше, чем в 2-замещенных производных.

Из приведенных данных следует, что при определении химических сдвигов алкилрезорцинов наблюдаются весьма регулярные эффекты как гидроксильной группы, так и алкильных заместителей. Этим еще раз подтверждается аддитивность влияния заместителей в ароматических соединениях. В то же время оказывается, что накопление заместителей у соседних атомов ароматического ядра приводит к дополнительному изменению химических сдвигов стерически взаимодействующих атомов. Стерическое взанмодействие очень ярко отражается на экранировании насыщенных углеродных атомов боковой цепи.

Таким образом, из углеродных спектров ЯМР алкилрезорцинов вытекает следующая структурная информация.

1) На основе спектров монорезонанса очень просто определить число замещенных атомов ароматического ядра.

2) Возможно определение положений заместителей по соображениям симметрии и по химическим сдвигам углеродных атомов ароматического. ядра и алкильного заместителя.

3) Прямым способом определяется число углеродных атомов в алкильном заместителе.

4) Возможно определение структуры алкильного заместителя. При этом можно исходить из расчетных [10] или из экспериментальных химических сдвигов соответствующих углеводородов с учетом стерических эффектов и влияния ароматического цикла. 
1. Лилл е Ю. Э., Химия твердого топлива, 4, 107 (1969).

2. Wenkert E., Loeser E.-A., Mahapatra S. N., S chenker F., Wilson E. M., J. Org. Chem., 29, 435 (1964).

3. Лилле Ю. Э., Кундель Х. А., Тр. Ин-та сланцев, 16, 186 (1967).

4. De 11 H. D., Ka m p R., D o ersing M., J a n s en H., Ann., 709, 70 (1967).

5. Л ил л е Ю. Э., П ей н а р У. Л., Б и т т е р Л. А., Тр. Ин-та сланцев, 19 (в печати).

6. Occolowitz I. L., Anal. Chem., 36, 2177 (1964).

7. Лилле Ю., Биттер Л., Мурд А., Пейна У., Тр. Ин-та сланцев, 19 (в печати).

8. Schug J. C., Deck J. C., J. Chem. Phys., 37, 2618 (1962).

9. Witiak D. T., Patel D. B., Lin Y., J. Am. Chem. Soc., 89, 1908 (1967).

10. G r a n t D. M., P a u 1 E. G., J. Am. Chem. Soc., 86, 2984 (1964).

11. Лилле Ю., Би т те р Л., Пей н а р У., Изв. АН ЭССР, Хим. Геол., 18, 365 (1969).

12. В а л т е Р. Э., Н ейланд О. Я., Изв. АН ЛатССР, Химия, 710 (1968).

13. Л илле Ю. Э., Би т те р Л. А., Тр. Ин-та сланцев, 18, 127 (1969).

14. Л ил л е Ю. Э., Бит т е р Л. А., Мурд А. Т., Тр. Ин-та сланцев, 19 (в печати).

15. L i p p m a E., P eh k T., P a st J., ENSV TA Toimet,, Füüs. Matem., 16, 345 (1967).

16. A a rn a A., Suomen Kemistilehti, B 42, 217 (1969).

17. Пехк Т., Ли п п м а Э., Изв. АН ЭССР, Хим. Геол., 19, 372 (1970).

18. Li p pma a E., P eh k T., ENSV TA Toimet., Keemia. Geol., 17, 210 (1968).

19. Пехк Т., Р анг С., Э йзен О., Липпм а а Э., Изв. АН ЭССР, Хим. Геол., 17, 296 (1968).

20. Suhr H., Anwendungen der kernmagnetischen Resonanz in der organischen Chemie, Springer, 1965.

21. La u ter bur P. C., J. Am. Chem. Soc., 83, 1838 (1961).

22. Woolfenden W. R., Grant D. M., J. Am. Chem. Soc., 88, 1496 (1966).

23. L a u ter b u r P. C., J. Am. Chem, Soc., 83, 1846 (1961).

24. Пехк Т., Ли п п а а Э., Беликова Н. А., Платэ А. Ф., ДАН СССР (в печати).

25. Kroschwitz J. I., Winokur M., Reich H. J., Roberts J. D., J. Am. Chem. Soc., 91, 5927 (1969).

26. Пехк Т., Липпм а а Э., Изв. АН ЭССР, Хим. Геол., 17, 195 (1968).

27. Dh a mi K. S., S to ther s J. B, Can. J. Chem., 44, 2855 (1966).

$\begin{array}{cc}\text { Институт кибернетики } & \text { Поступила в редакцию } \\ \text { Академии наук Әстонской ССР } & 14 / \mathrm{IV} 1970 \\ \text { Институт сланцев (2. Кохтла-Ярве) } & \end{array}$

T. PEHK, O. LILLE, E. LIPPMAA, L. BITTER

\section{ALKUOLRESORTSIINIDE SUSINIK-13 KEEMILISED NIHKED}

Määrati süsinik-13 keemilised nihked 2-, 4- ja 5-asendatud $n$-alküülresortsiinides ning mōnedes alküülbenseenides. Süsinik-13 spektroskoopia on edukalt kasutatav alküïilfenoolide struktuuri määramiseks. Hōlpsasti on määratavad aromaatse tuuma asendatud aatomite arv, asendajate asukohad ning alküüırühmade struktuur. Aromaatse tuuma suhtes $\alpha$ - ja $\beta$-asendis asuvate aatomite varjestus sōltub steerilistest mõjudest.

T. PEHK, O. LILLE, E. LIPPMAA, L. BITTER

\section{CARBON-13 CHEMICAL SHIFTS OF ALKYL RESORCINOLS}

Carbon-13 chemical shifts of 2-, 4- and 5-substituted $n$-alkyl resorcinols and some alkyl benzenes were measured from double resonance spectra. It is shown that carbon-13 NMR spectroscopy can be successfully used for the determination of substituent positions in the aromatic ring and for the structure elucidation of alkyl side chains. The shielding of alkyl carbon atoms in $\alpha$ and $\beta$ positions in respect to the aromatic ring is influenced by steric interactions between the substituent groups. 